\title{
INTERVIEW
}

\section{An Interview with Ohio University Associate Professor of CALL Greg Kessler}

\author{
Victoria Antoniadou \\ Universitat Autònoma de Barcelona, Barcelona, Spain
}

(Final version received 26 April 2013)

Dr. Greg Kessler is Associate Professor as well as the Director of the Language Resource Center in the College of Arts \& Sciences at Ohio University $^{1}$. He has authored and co-authored numerous book chapters and articles in the field of CALL, such as Does teachers' confidence with CALL equal innovative and integrated use? (2008, with L. Plakans); Formal and informal CALL preparation and teacher attitude toward technology (2007); Developing collaborative autonomous learning abilities in computer mediated language learning: Attention to meaning among students in wiki space (2010, with D. Bikowski); The influence of SLA training in curricular design among teachers in preparation $(2011$, with D. Bikowski). He has also published in renowned educational technology journals such as TESOL, Language Learning \& Technology, and CALICO. Dr. Kessler is currently president of the Computer Assisted Language Instruction Consortium (CALICO) and editor of the Action Research Column for the journal Language Learning \& Technology. He has co-authored the TESOL Technology Standards Framework as well as the full volume,TESOL Technology Standards: Description, Implementation, Integration. Dr. Kessler is currently chair of the Faculty Technology Advisory Group and a member of the Information Technology Governance Council at Ohio University. He has conducted seminars about the convergence of language and technology around the world.

INTERVIEWER: You have been somewhat of a pioneer in the use of technology and SL teacher learning. What developments have you seen over the last few years that you feel have really had an impact on language teaching and learning?

KESSLER: I am thinking that in just the last few years there has been much more of an appreciation and awareness of the variety of technology tools that can be used in the classroom in and outside the classroom. I think that social media has probably played the biggest role in this. People, just regular teachers, are becoming more comfortable using all different kinds of technology social media different technologies that they might have not used in the past and there is a tipping point where they are then willing to actually try them in the classroom and once they do they realize that students find it engaging and that there is a meaningful response so I think it is just as our culture becomes more technologically-savvy there is an effect on the 
classroom. It may not be a huge effect unfortunately but it is more than you know there is a small group of us who have been kind of pushing this for years and you know just 5-10 years ago very few teachers were willing to try any new experimentation with technology in the classroom and now I think people are much more willing to give it a try. I think they recognize the potential. Even if they don't feel comfortable they recognize that there is some potential for trying it.

INTERVIEWER: What technologies are we talking about exactly, networks or ICT?

KESSLER: Well, it could be anything. I mean I am really trying to promote a lot of use of social media like you know whether it is Wikipedia or Facebook or Google Plus or some of the things that people just use normally in their daily lives. I think you know they can be used easily in language classrooms as well and it is not a difficult leap. It is not an extension. It is not. It is just a natural way of communicating today.

INTERVIEWER: But what about Facebook? Are you actually using Facebook in the classroom?

KESSLER: Yeah, we have had some classes where we actually use it as a learning management system. It is a very social learning management system and here I have seen it used in a couple of different places. Here, in the States, it can be a little bit tricky because students see it as their own personal space, for social interaction but I have seen teachers use it in other parts of the world, especially in Asia where the students really enjoy it as a learning tool so maybe there is a different attitude towards these different tools in different contexts and cultures.

INTERVIEWER: Facebook as a learning management system. This is very innovative. Could you tell us a bit more about it?

KESSLER: Well, it gives you lots of opportunities for continued practice, right? And depending on how large the group is I mean this could be a private group in Facebook you get feedback from a variety of interlocutors so maybe it's an online exchange between two schools? And instead of it being a kind of very traditional conventional academic ICT interaction, it is mimicking the same kind of social interactions that we have on Facebook, which may be less threatening and may be a little bit more comfortable for people.

INTERVIEWER: In 2007 you wrote an article about teacher attitudes, outlining how most teachers get their concepts of technology innovation through informal mediums rather than formal situations. Do you think this has changed in the last 5 years? Changed for the better?

KESSLER: I think there has been a significant increase in the amount of formal preparation that is being done. And just to make it clear, the distinction between these two is really I mean formal preparation is simply a traditional kind of academic course or a program of courses so it is actually studying something in the context of a formal educational environment but I think it is still lacking. I see there are language teacher preparation programs around the world that now 
incorporate some elements of CALL and now they may have a CALL component in a methodology course, they may have a whole course that is devoted to CALL, they may have a whole programme that is devoted to CALL but still, it is not everywhere. There is still a lot to be desired but there is much more. It has been growing and there is much more interest all the time.

INTERVIEWER: On the international level or in the United States?

KESSLER: Well, it is hard for me to judge on the international level. I kind of try to observe things here and I think it probably represents attempts that are happening elsewhere. I know people around the world who are involved in this and I hear from them once in a while but I really don't know. I think in Europe there is also much of this extension of these programs that has been driven by standards-based projects, right? And I know that the European Higher Education Area includes a component about technology and so I think that that kind of raises the bar, it forces programs to incorporate technology in these preparations so I think that on one level it is impossible to deny the fact that it has to be involved somehow. But how? Like I said you could get a Master's degree in CALL or you could mention it one day in class. I was involved with the TESOL technology standards, which are primarily North American-based and are intended to be used internationally and across contexts so they are intended to be used in K12 settings in higher education and adult education all over the place, even private language schools. I think that is playing a role. I think that these projects are making administrators more aware of the need to integrate these kinds of programs. But I think the majority of these preparations are still being done in informal ways. But one thing that I have observed since writing that is I think that the informal preparations are probably being done much better now. I think people are much more aware of the need to focus on pedagogical goals and not just here is a flashing new tool that I want to teach you. I think the standards-based programs have helped people realize how they might focus their attention in this way. It has helped raise awareness and I see much more focusing on that division today because I think that the informal training has come a long way.

INTERVIEWER: And this brings me to my next question, what should exactly be understood as informal CALL instruction?

KESSLER: Well, the idea behind this was to compare people who were receiving training inside of a degree program that was a component of a degree program with those who were just attending workshops or being part of a community of practice or any of the various other ways that you can incidentally receive knowledge about CALL.

INTERVIEWER: Like experiential learning?

KESSLER: Right. Well I guess experiential learning would happen with either one. It is just that if you are doing the formal training and also having the experience I think that is better. I think the experiential learning is beneficial no matter what. But I think that the formal training 
allows for a comprehensive overview of a lot of the stuff that has come before that simple experience won't compensate for.

INTERVIEWER: Could you describe a formal training course that you have seen?

KESSLER: Sure, so that kind of a course should cover everything that this field has been doing in the last 25-30 years which provides a lot of background and how people were using much earlier tools and I think how exactly they reflected on that use and how the ideas have evolved over time. I think having a deeper knowledge about all that can inform what we do today. Just jumping in and getting experience simply might mean that you will make all the same mistakes that people have learned from in the past. So that is one way of thinking about it. So you can learn from other people's mistakes. I guess that is an easy way to put it. But another thing to consider is that people have viewed the use and role of technology through a lot of different lenses, a lot of different methodological lenses and a lot of different theoretical lenses over the last few decades. This can really help people think in different ways and view the integration of technology in the language classroom through different lenses. I think that can really help us maybe rethink the way that we do things.

INTERVIEWER: That would be related to what you have called contextualized instruction?

KESSLER: Right.

INTERVIEWER: And do you see any beneficial aspects of this informal component of CALL instruction?

KESSLER: Well, I think informal preparation is better than no preparation. I don't think it can be as comprehensive, provide as much of a background or as much exposure to the previous ways of thinking that have existed but I think there is probably a lot of variety with informal preparation as well. Imagine if you are engaging in a number of workshops that are organized by the same group of people or by the same person over a period of time. I think that that really gets to be almost like what I would consider formal. I guess the other extreme of informal preparation is you attend a one-hour webinar one time about something. That is the extreme of informal. You are not even face to face with somebody, it's not extended it's not contextualized for your teaching context and it is very easy to make little connection between that and what you are actually doing in your real practice. So that is I guess the biggest problem with most informal preparation.

INTERVIEWER: And that goes back to what you were saying before about incidental learning? 
KESSLER: Yes, I think that most informal preparation is going to be very incidental. You know you go to a conference and you attend a workshop. Everybody else in the conference probably comes from a different background than you do, the workshop is being generalized to apply to everybody and so it can't be very contextualized. If you have the opportunity to have similar training, if it is something that is in-service training at your institution then that is going to be contextualized. I think that is going to be much better than a one-shot informal kind of a workshop.

INTERVIEWER: In the 2007 paper, you also talk about extremely positive experiences with CALL as essential in order to achieve attitudinal change towards technology, which can in turn enable integration in teaching practices. From your experience, could you describe what may constitute such extremely positive experiences in formal CALL instruction that can provide these strong and necessary incentives for teachers to overcome the manifold challenges they face when it comes to integrating technologies in their teaching?

KESSLER: Yes, this was published in 2007 but it was actually written in 2005 so it has been quite a long time and part of the reality of that situation is at that point in time there was basically a small portion of teachers who really appreciated what CALL could offer them and the vast majority of language teachers were scared to death of CALL. So that plays a big role in this kind of perspective; it is almost like you know when the majority of people don't appreciate something and you do maybe your attitude toward it is more extreme than it would be otherwise, almost in an opposite perspective so it makes you kind of hold on to it and kind of celebrate it even more. I think very early on it was very easy to see some significant benefits that preceded lots of social media, this preceded the majority of things that we might be doing with technology today in a language classroom so it's a very different world from what it was eight years ago, which is surprising but it seems to me like this kind of ties in with some of the things we have been talking about already and in this kind of comprehensive formal preparation you never know what topic is going to really get a potential teacher excited and really engaged and when you have this kind of comprehensive coverage of the history of the field of CALL it is often some little unanticipated minor topic that will get one person really interested and you can never anticipate that or prepare for that in a two-hour or a three-hour exposure to the field and I have students all the time who find one aspect of a class to be the most fascinating thing they have ever thought about and they focus on that in their dissertation or the work that they do for the future and I am always surprised by that. They get excited by one little kernel, one little detail and I guess that is the thing -there is so much potential because it is such a diverse and broad field and there are so many things that people could find exciting; for every individual it is something different and it has been growing and growing and growing to the point where I mean you don't even see a lot of people today writing about CALL because it is kind of too big to do so we are focusing on little areas, right? I continue to want to write about the whole area because I still see it as being a cohesive field that I think we benefit from all living under one big tent. 
INTERVIEWER: So the key word here is comprehensive instruction and comprehensive instruction of CALL as a broad area?

KESSLER: Yeah and in conjunction with that in a lot of my classes a lot of what we cover ... a lot of people wouldn't consider it to be CALL but they are also covering just the wide variety of digital communication potential so it might be related to just cultural observation of how our communication has changed using digital tools that haven't necessarily been used for language instruction but it is obvious that they have a lot of potential for language instruction, extended language practice.

INTERVIEWER: In the light of contextualized CALL instruction for teacher development and sustainable or long-term results, how do you see the relevance and potential of experiential network-based learning using modern and not outdated technology?

KESSLER: Well, I think it is extremely relevant. I think the experiential learning is really critical but I think not everybody agrees on what that means. I could go out and experience the world by myself or I could experience the world as a member of a group of communicators with a critical reflection on my experience and I think that is really the most valuable form of experiential learning. Giving the opportunity to reflect, having others provide me with feedback whether it is my peers or an instructor but that reflection and that participation in a community of communicators is really important.

INTERVIEWER: And how do you see sustainability of results in what we have discussed earlier about really positive, extremely positive experiences, should we hope that those teachers are going to implement technologies in the future and continue learning about that?

KESSLER: That is a big challenge. First of all, I would hope that they would use the technology when it is appropriate. I think that a lot of people feel like they just need to use it as much as possible. I am not in favor of promoting people to use technology when it is not really going to be beneficial. There are still things that should be done face to face or maybe even on paper and that is fine. There is a role for that still but the bigger issue is with sustainability and continuing to try to use new things. It is not even a matter of continuing because it is really a matter of continuing to learn about new tools, new opportunities, new potentials, and new ways of thinking about new forms of communication and that is going to be constantly changing throughout our lives. I find that that is really the most exciting thing about this field. The way that we communicate today online is something that nobody could have anticipated 20 years ago. And for language learning it is fantastic. It is one of the best things that could have ever happened in the teaching of language, to the use of language. In fact, people are communicating with others that they would have never been able to communicate with, in ways they never could have communicated, for purposes that they would have never thought about communicating so it 
is fantastic. It is just amazing and I can only imagine that it is going to continue to change. Yet, our pedagogical practices are still generally the same as they were 20 years ago so I think that we need to be re-examining our pedagogical practices and they ought to reflect the way that these tools have changed and the way that our communication has changed. Something that I wrote in 2012 in an article in Language Learning \& Technology was referring to this evolving pedagogical practice model where we have this evolution of tools, evolution of communication, purposes, styles et cetera and we really need to think about how our pedagogy should be evolving as well.

INTERVIEWER: So in this evolving and constantly-changing world and tools and technology and ways of communication, is confidence the only stable variable that we need to invest in?

KESSLER: Well, in my classes we actually talk about this sustainability idea and we spend a good deal of time trying to anticipate how we might think about new tools so we even discuss hypothetical tools, tools that don't exist yet and what we might do with those and I have found that confidence is really important. A confident teacher doesn't mean somebody who is completely certain that everything is going to always work, right? It means somebody who is willing to take some risks and is confident that no matter what happens I can find a way out of this situation, recover from this situation. It probably could be unpacked a lot but it is not even just confidence I think it is curiosity and flexibility that play a role in this, as well. Maybe confidence is really a demonstration of their willingness to try new things.

INTERVIEWER: So the difficult thing is to promote this confidence and to provide enough experiences for them, enough pitfalls let's say, enough limitations or problems for them to develop this confidence and willingness to make it more sustainable maybe?

KESSLER: That is a good question I think there are ways that you can promote this. I think you can make it clear. As people get more experience teaching, I think they can develop more willingness to take chances, to do new things and this is not isolated to the use of technology -I mean this is true for any teachers. We probably all develop much more confidence in our ability to teach the more experience we get teaching. Of course, everybody is afraid of change to some degree. Some of us are much more willing to embrace change than others. I think some people are just naturally very confident. And in fact that may not be ideal; some people are overconfident. I did a study a few years ago that looked at this contextualized used of CALL and over-confident teachers were the ones who really did some things that were questionable that weren't really well thought out. The teachers who were less confident but willing to try risks were the ones who really integrated CALL most appropriately for their pedagogical purposes. And I think that was a really interesting observation and I would have never anticipated that. It was not the purpose of that. That was the natural outcome of that observation. I found it really 
interesting because prior to that, I would have just thought you know everybody needs to be more confident.

INTERVIEWER: So what do you think should be understood as "really integrating technology into teaching practices"? And what are the main competences needed for language teachers to be able to 'really' integrate technology into their teaching practices?

KESSLER: Right, well this idea of really integrating technology is related to what I was talking about earlier about re-thinking our pedagogical purposes and activities and practices. And this means that instead of taking our traditional forms of education and forcing whatever technology we want to use into that model we should build wholly completely new types of goals and lessons around the strengths of the technology. So things might function very differently, our group work might be done in a very different way. Our locations in respect to one another in the learning process might be very different and it might be for a variety of different reasons but starting by identifying the strengths and the potential of technology in juxtaposition with the learning goals and backgrounds and contexts of the learners. I think there is a lot of thinking to be done on this; I am just beginning to scratch the surface. I hope that others start scratching with me.

INTERVIEWER: You talk about learner autonomy and CALL - do you foresee language learning becoming a more individualized practice, facilitated through distance learning or is it best facilitated through blended learning? How must teachers and students adapt to these new practices?

KESSLER: Well, I think that language learning to some extent has always been an individual practice. It has always been kind of individualized. The model of autonomy that I have worked with is completely dependent upon students being autonomous members of a group so it is about them being responsible for their own learning, aware of the role that they play in their own learning, knowing how well they interact with others as a member of a group, knowing what their strengths are, what their weaknesses are, what they need to work on so it is really this awareness that helps them manage, control and make the most of their own learning. And then, it is in this context of the collaborative autonomous language learner, which means that by better knowing who they are, they are better able to participate as a member of a language learning community or group and collaborate. That is kind of my idea on that. Now, whether that happens through blended learning or distance learning or face to face learning, I think that is somewhat incidental. It may work in all those various forms. I think that some people really thrive online, some people probably really really thrive face to face maybe there are some who like the mix so blended learning would be ideal for them. But I think that is not as important as the kinds of activities and the kinds of interactions and the kinds of the ways that people are encouraged to help each other as collaborative members of community. 
INTERVIEWER: And extending the previous question, do you foresee contextualized computer-assisted and/or network-based teacher preparation becoming a mainstream practice in teacher education? Can the efforts and developments available to-date account for such future?

KESSLER: I do see this becoming a mainstream practice. I hope that is happening. There is certainly a trend in movement in that direction. The job market calls for it, I observe language teacher job ads all the time and they seem to be including a request for knowledge about technology more and more all the time. In this country at least. I don't know what is happening everywhere else but I do observe it here. I think again these standards-projects are calling for this so that is really good. There are some people, I don't know if you are familiar with the work of Steven Bax, he is very popular in Europe but he has made claims for over a decade now that CALL has already been or should be normalized, as he calls it and that means it is a standard part of the curriculum. I don't think we have seen that, I think he is over-ambitious with that and the way he describes that as being so normal and such a natural part of language teacher preparation that we don't need to focus on that as a separate discipline and that is where we begin to disagree about these things because I think it is so unique and it has so much potential and it is not so integrated yet. I think that we really do need to focus on it but I do think it is moving toward becoming mainstream practice.

\section{References}

Kessler, G. (2007). Formal and informal CALL preparation and teacher attitude toward technology. Computer Assisted Language Learning, 20(2), 173-188.

Kessler, G., \& Bikowski, D. (2010). Developing collaborative autonomous learning abilities in computer mediated language learning: Attention to meaning among students in wiki space. Computer Assisted Language Learning, 23(1), 41-58.

Kessler, G., \& Bikowski, D. (2011). The influence of SLA training in curricular design among teachers in preparation. CALICO Journal, 28(2), 522-545.

Kessler, G., \& Plakans, L. (2008). Does teachers' confidence with CALL equal innovative and integrated use? Computer Assisted Language Learning, 21(3), 269-282.

${ }^{1}$ Contact: kessler@ohio.edu

Websites : http://www.ohio.edu/linguistics/people/kessler.html

https://sites.google.com/site/gregkkessler/ 
Author references:

Victoria Antoniadou is a $\mathrm{PhD}$ candidate in Language and Literature Education at the Universitat Autònoma de Barcelona. Her research draws upon the sociocultural-historical line of thought regarding learning and development as a lens to explore teacher learning trajectories over lengthy periods of time. Her dissertation incorporates the investigation of teacher learning in the making i.e., process and outcomes, as it unfolds in a blended configuration of online and offline spheres of participation, social interaction and multiple resources.

Email: Victoria.Antoniadou@e-campus.uab.cat

To cite this article:

Antoniadou, A. (2013). An interview with Ohio University associate professor of CALL Greg Kessler. Bellaterra Journal of Teaching \& Learning Language \& Literature, 6(2), 99-108. 